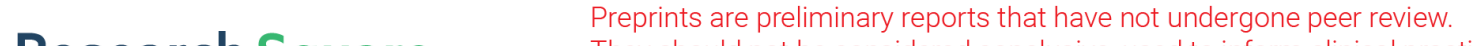 \\ They should not be considered conclusive, used to inform clinical practice, \\ or referenced by the media as validated information. \\ Choice between home and health institutional births in the era of Kenya's maternity subsidy
}

\section{Abednego Muema Musau ( $\nabla$ mbelemusau@gmail.com )}

University of Nairobi College of Humanities and Social Sciences https://orcid.org/0000-0001-5979-

1191

\section{Tabitha Kiriti Ng'ang'a}

University of Nairobi College of Humanities and Social Sciences

\section{Research article}

Keywords: Choice, place of birth, home delivery, institutional birth, maternity subsidy, maternal outcomes

Posted Date: January 23rd, 2020

DOI: https://doi.org/10.21203/rs.2.21697/v1

License: (1) This work is licensed under a Creative Commons Attribution 4.0 International License.

Read Full License 


\title{
CHOICE BETWEEN HOME AND HEALTH INSTITUTIONAL BIRTHS IN THE ERA OF KENYA'S MATERNITY SUBSIDY
}

By

\author{
Abednego Musau ${ }^{1}$ \\ and \\ Prof. Tabitha Kiriti Ng'ang'a ${ }^{2}$
}

Paper submitted to Journal of Health Population and Nutrition on January 16, 2020

\footnotetext{
${ }^{1}$ Corresponding author: School of Economics, University of Nairobi, Mbelemusau@gmail.com, +254 721246450

${ }^{2}$ Professor of Economics, School of Economics, College of Humanities and Social Studies, University of Nairobi
} 


\begin{abstract}
Background

Adverse maternal and neonatal outcomes disproportionately afflict low and middle-income countries, which experience high-unmet need for safe and skilled attendance at birth. This study sought to investigate how choices for place of birth were made in Kenya during the era of a national maternal subsidy.
\end{abstract}

\title{
Methods
}

The study employed data from the Kenya Demographic Health Survey 2014 and involved data from women who experienced a birth around the time when the maternity subsidy was in place. After testing for multi-collinearity of variables and addressing endogenous endogeneity using two-stage residual inclusion, probit regression models were estimated. The choice for place of birth was employed as a binary outcome variable.

\section{Results}

Overall, data from 4,772 women were included in the analysis. The women's mean age was 27.7 years and majority $(83.8 \%)$ were married or staying with their sexual partners. Among these women, $2748(57.5 \%)$ had elected institutional births. Regression analysis illustrated that woman's age, the woman and partner's education, economic empowerment, low parity, low county poverty headcount rate and access to medical insurance. Further, access to complementary reproductive services such as antenatal care and family planning and the existence of the maternity subsidy were associated with increased likelihood to choose deliveries in health facilities.

\section{Conclusions}


The existence of the maternal subsidy confers women increased potential to elect health institutions as a preferred place for birth, although this was influenced by other factors. These findings imply that investments, which prevent teen pregnancies, reduce domestic and national poverty, increase education attainment, expand autonomy of women in decision making and promote access to the continuum of reproductive health services can optimize choice making during the existence of the maternity subsidy favoring access to safe institutional births.

\section{Key words}

Choice, place of birth, home delivery, institutional birth, maternity subsidy, maternal outcomes 


\section{Introduction and Background}

Kenya, a lower middle-income country in SSA, has experienced both a high maternal mortality ratio (MMR) ranging between 360-750 deaths/100,000 births and a high neonatal mortality rate (NMR) ranging between 19.9-39.1/1,000 births. Kenya launched a maternity subsidy in terms of free maternity services (FMS) in 2013 through a budgetary allocation of Kshs. 3.7 billion. These funds were to be channeled to county government-run health facilities, faith-based and national referral hospitals and sought to provide direct re-imbursement of service providers in public and selected private facilities for any skilled deliveries conducted. A $22 \%$ and $17 \%$ point rise in skilled birth attendance for normal and caesarian deliveries respectively was the anticipated immediate outcome. The subsidy sought to remove service-related costs, through fee exemption to encourage poor women to access skilled attendance at birth.

Anecdotal evidence reports increased interest among women to access institutional births. The subsidy has received accolades from policy makers (1)(2). However, it is plagued by multiple implementation challenges which prevent optimal attainment of its goals (3-5). Many women continued to deliver at home despite the fee-for-service exemption. It seems that how women and their families make decisions about where to deliver is determined by factors other than the anticipated cost of the services. This study investigates these factors in order to unearth determinants of choice of place of birth between home and institutional delivery during the era when the subsidy is actively being implemented. The study uses nation-wide data from the Kenya Demographic and Health Survey (KDHS) 2014, which was collected using a robust sampling criteria and sought to examine decision making for place of birth and compare these during and prior to the subsidy. 


\section{Analytic framework}

According random utility theory (RUT), when a woman is presented with two alternatives regarding where to deliver their baby (at home or in a health institution), a rational individual will prefer the choice which maximizes utility. Choice theory assumes a decision-maker is adequately informed of the benefits and risks for each choice and is rational. This study uses random utility principles to determine the choice of place of delivery during the era of an existent subsidy. The differences in the utility between a home and institutional delivery is determined by the probability of selecting one of the two choices and can be presented as a probability function which can be derived using a probit model.

A probit model applies in decision-making circumstances when the dependent variable has binary categories and demands that there should always be a reference category against which the probability of the other choice is computed. Additionally, a probit model assumes that the errors terms $\boldsymbol{\varepsilon}$ are normally distributed. The probability that a random woman will choose to deliver in a health facility can be computed using equation 1.

$\mathbf{y}^{*}=\mathbf{X}^{\mathbf{T}} \boldsymbol{\beta}+\varepsilon$

Where $\mathbf{y}^{*}$ is the place of birth; $\boldsymbol{\beta}$ are the estimated coefficients, $\mathbf{X}^{\mathbf{T}}$ are vectors representing the unique characteristics of the woman as well as the socio-economic and health system factors; and the error term $\boldsymbol{\varepsilon} \sim \boldsymbol{N}(\mathbf{0}, \mathbf{1})$. The signs and magnitude of the coefficients for each of these characteristics can be estimated and the marginal effects for the two choices of place of birth can be computed. Further, the probability of a woman choosing either a home or an institutional delivery can be expressed using a multivariate regression model using her unique characteristics. 
These include individual maternal factors, socio-economic factors, perceived benefits, accessibility of health institutions and access to an economic subsidy.

The probit model for the choice for either a home or an institutional delivery $\mathbf{y}$ can be expressed in equation 2 where $\mathbf{y}=\mathbf{1}$ for institutional delivery and $\mathbf{y}=\mathbf{0}$ for home delivery. The log of an institutional delivery is a function of individual maternal factors, socio-economic factors, perceived benefits, accessibility of health institutions and access to economic subsidy. This can further be expanded with the variables of the study as shown on equation 2 .

$\log y_{i}=\beta_{0}+\beta_{1} \mathrm{~A}+\beta_{2} \mathrm{MS}+\beta_{3} N C+\beta_{4} S H+\beta_{5} R A+\beta_{6} L O E+\beta_{7} P E+\beta_{8} O L+$
$\beta_{9} R+\beta_{10} W I+\beta_{11} P I+\beta_{12} D M+\beta_{13} A H+\beta_{14} P E+\beta_{15} I+\beta_{16} N B++\beta_{17} A N C+$
$\beta_{18} A C+\beta_{19} F P+\beta_{20} T+\varepsilon$

On equation $2, \log y_{i}$ is the dependent variable which is either a home or institutional delivery. A home delivery is defined as a birth conducted at home or in any other place apart from a health facility while an institutional delivery is defined as a delivery conducted in a health delivery. Home delivery was the reference category. Independent variables consisted of individual women characteristics where $\mathrm{A}=$ age in years, $\mathrm{MS}=$ marital status, $\mathrm{NC}=$ number of children, $\mathrm{SH}=$ size of household, RA=religious affiliation and $\mathrm{LOE}=$ level of education. Socio-economic factors include $\mathrm{PE}=$ paid employment, $\mathrm{OL}=$ ownership of land, $\mathrm{R}=$ residence (urban versus rural), WI=household wealth index score, $\mathrm{PI}=$ county poverty head count rate, $\mathrm{DM}=$ decision making on food, $\mathrm{AH}=$ age of household, $\mathrm{PE}=$ partner's education and $\mathrm{I}=$ existence of insurance. Perceived benefits include $\mathrm{NB}=$ number of previous births, $\mathrm{ANC}=$ adequacy of antenatal care, $\mathrm{AC}=$ place of access to ANC, FP=previous Family Planning use. $\mathrm{T}=$ Time of subsidy is a dummy variable created to differentiate the period prior and during the maternal subsidy. 
To increase the validity of the results, multi-collinearity tests were conducted to determine the most robust variables for the model, dropping variables with high collinearity. Additionally, the probit model from the first stage was subjected to two stage residual inclusion (2SRI) to address potential endogeneity as suggested by Terza, Basu and Rathouz(3). Adequate ANC attendance was employed as the endogenous regressor and woman's level of education and number of previous births used as instrumental variables.

Data was sourced from the Kenya demographic and health survey conducted between May and October 2014. The survey employed a nationally representative sample. Respondents were drawn from 36,812 households from which 31,079 women aged 15-49 were interviewed representing a response rate of $96.6 \%$. The population of interest was women aged 15-49 years who gave birth in the five years preceding the survey. Among women who experienced a birth in the five-year period, only a subset of women who reported a birth in a 30-month period leading to end of the survey in October 2014 were included in this analysis (15 months prior and 15 months after maternity subsidy was approved). The study analyzed secondary data containing no identifiable information on the respondents, which is freely available to the public upon fulfilling a data request and no ethical considerations were required.

\section{Study findings}

This study analyzed data from 4,772 women who experienced a delivery during the period of interest among 9,892 women who completed the full women questionnaire. Table 1 summarizes the frequencies, mean, standard deviation, minimum and maximum values for all variables. Women included in the analysis were of medium age with a mean of 27.8 years (standard deviation=6.477) and age ranging between 15 - 49 years. 
Table 1: Summary statistics of the study variables $(n=4,772)$

\begin{tabular}{|l|c|c|c|c|c|}
\hline Variables & Frequency & Mean & Std. Dev. & Min. & Max. \\
\hline Woman's age & 4772 & 27.7745 & 6.477 & 15 & 49 \\
\hline Marital status & 4000 & 0.8382 & 0.368 & 0 & 1 \\
\hline Age of household head & 4772 & 37.763 & 12.698 & 15 & 95 \\
\hline Number of children & 4772 & 3.227 & 2.116 & 0 & 12 \\
\hline Number of births & 4772 & 3.4564 & 2.314 & 1 & 14 \\
\hline Woman's education & 1281 & 0.2684 & 0.443 & 0 & 1 \\
\hline Partner's education & 1487 & 0.3116 & 0.463 & 0 & 1 \\
\hline Owning land & 372 & 0.078 & 0.268 & 0 & 1 \\
\hline Size of household & 4772 & 5.764 & 2.444 & 1 & 19 \\
\hline Makes food decisions & 3215 & 0.6737 & 0.469 & 0 & 1 \\
\hline Residence & 1583 & 0.3317 & 0.471 & 0 & 1 \\
\hline Wealth index factor score & 4772 & -21160.34 & 98414.90 & -248010 & 340346 \\
\hline Paid employment & 2138 & 0.4498 & 0.498 & 0 & 1 \\
\hline Religious affiliation & 3827 & 0.802 & 0.399 & 0 & 1 \\
\hline Poverty headcount rate & 4772 & 27.333 & 9.755 & 16.7 & 47.4 \\
\hline Health insurance coverage & 605 & 0.1268 & 0.333 & 0 & 1 \\
\hline Use of family planning & 3066 & 0.6425 & 0.479 & 0 & 1 \\
\hline Place of ANC attendance & 4434 & 0.9292 & 0.257 & 0 & 1 \\
\hline Adequate ANC & 2520 & 0.5281 & 0.499 & 0 & 1 \\
\hline Time of the subsidy & 2429 & 0.509 & 0.5 & 0 & 1 \\
\hline Institutional birth & 2748 & 0.5759 & 0.494 & 0 & 1 \\
\hline Private facility birth & 574 & 0.2089 & 0.407 & 0 & 1 \\
\hline Sourc: Authors Calculatong
\end{tabular}

\section{Source: Author's Calculations}

\section{Empirical model results}

The results of the first stage empirical model on the choice between institutional versus home delivery are summarized on Table 2 .

Table 2: Estimates of choice between health facility and home delivery $(N=4,772)$

\begin{tabular}{|l|c|c|l|l|c|c|}
\hline $\begin{array}{l}\text { Institutional birth (home as } \\
\text { reference) }\end{array}$ & \multirow{2}{*}{ Coefficient } & \multirow{2}{*}{ S.E. } & \multirow{2}{*}{$\mathbf{z}$} & \multirow{2}{*}{$\mathbf{P} \mathbf{z}$} & \multicolumn{2}{|l|}{$\mathbf{9 5 \%}$ C.I. } \\
\hline Woman's age & $0.0190^{* *}$ & 0.0056 & 3.37 & 0.001 & 0.0079 & 0.0301 \\
\hline Marital status & -0.1027 & 0.0793 & -1.3 & 0.195 & -0.2589 & 0.0527 \\
\hline Religious affiliation & -0.0522 & 0.0607 & -0.86 & 0.390 & -0.1713 & 0.0668 \\
\hline Poverty headcount rate & $-0.0085^{* *}$ & 0.0023 & 3.75 & 0.000 & 0.0041 & 0.0130 \\
\hline Woman's education & $0.2769^{* *}$ & 0.0595 & 4.66 & 0.000 & 0.1603 & 0.3934 \\
\hline Age of the household head & 0.0026 & 0.0020 & 1.27 & 0.205 & -0.0014 & 0.0065 \\
\hline
\end{tabular}




\begin{tabular}{|c|c|c|c|c|c|c|}
\hline Size of the household & -0.0117 & 0.0115 & -0.99 & 0.323 & -0.0339 & 0.0117 \\
\hline Owns land & -0.0385 & 0.0831 & -0.46 & 0.643 & -0.2014 & 0.1244 \\
\hline Paid employment & 0.0709 & 0.0449 & 1.58 & 0.114 & -0.0170 & 0.1588 \\
\hline Food decision & 0.0395 & 0.0588 & 0.67 & 0.501 & -0.0757 & 0.1547 \\
\hline Residence & $0.1547 * *$ & 0.0529 & 2.92 & 0.003 & 0.0510 & 0.2585 \\
\hline Wealth index factor score & $0.0001 * *$ & 0.0000 & 16.17 & 0.000 & 0.0000 & 0.0001 \\
\hline Partner's education & $0.1063^{*}$ & 0.0526 & 2.02 & 0.043 & 0.0032 & 0.2094 \\
\hline Health insurance coverage & $0.3520 * *$ & 0.0832 & 4.23 & 0.000 & 0.1888 & 0.5152 \\
\hline Adequate $\mathrm{ANC}$ attendance & $0.2471 * *$ & 0.0435 & 5.69 & 0.000 & 0.1619 & 0.3323 \\
\hline Place of ANC access & $0.9583 * *$ & 0.1155 & 8.3 & 0.000 & 0.7320 & 1.1847 \\
\hline Use of family planning & $0.1743^{* *}$ & 0.0505 & 3.45 & 0.001 & 0.0753 & 0.2733 \\
\hline Number of births & $-0.1196 * *$ & 0.0177 & -6.74 & 0.000 & -0.1544 & -0.0848 \\
\hline Time of the subsidy & $0.1649 * *$ & 0.0434 & 3.8 & 0.000 & 0.0799 & 0.2501 \\
\hline \multicolumn{7}{|c|}{$\begin{array}{l}\text { Number of obs. }=4772 ; \mathbf{L R} \mathbf{c h i}^{2}(\mathbf{1 9})=1853.80 ; \text { Prob }>\mathbf{c h i}^{2}<0.0001 ; \text { Pseudo } \mathbf{R}^{2}=0.2861 \\
\text { Log likelihood }=-2312.5367\end{array}$} \\
\hline
\end{tabular}

$* \mathrm{p}$ values $<0.05 ; * * \mathrm{p}$ values $<0.01$

Table 2 shows an $\mathrm{R}^{2}$ of 0.2861 , which implies that approximately $29 \%$ of the choices of the place to deliver (between a health facility and home) are influenced by the 19 explanatory variables included in this model. This means that $71 \%$ of the variance in the choices made about whether to deliver in a health facility or not can be explained by variables missing in this model. Of the 19 variables included in the analysis, 12 were statistically significant $(\mathrm{p}<0.05)$.

Results of the probit model in which 2SRI was employed are summarized on Table 3.

Table 3: Two-stage residual inclusion (2SRI) estimates of choice between health facility and home delivery $(N=4,772)$

\begin{tabular}{|c|c|c|c|c|c|c|}
\hline \multirow{2}{*}{$\begin{array}{l}\text { Home delivery as the } \\
\text { Reference }\end{array}$} & \multirow{2}{*}{ Coefficient } & \multirow{2}{*}{ S.E. } & \multirow{2}{*}{$\mathbf{z}$} & \multirow{2}{*}{$\mathbf{P}>\mathbf{z}$} & \multicolumn{2}{|l|}{ 95\% C.I. } \\
\hline & & & & & Lower & Upper \\
\hline Woman's age & $0.0192 * *$ & 0.0056 & 3.43 & 0.0010 & 0.0082 & 0.0303 \\
\hline Marital status & -0.0983 & 0.0815 & -1.21 & 0.2280 & -0.2582 & 0.0614 \\
\hline Religious affiliation & -0.0467 & 0.0599 & -0.78 & 0.4350 & -0.1641 & 0.0707 \\
\hline Poverty head count rate & $-0.0088 * *$ & 0.0023 & 3.85 & 0.0000 & 0.0043 & 0.0133 \\
\hline Woman's education & $0.2727 * *$ & 0.0606 & 4.5 & 0.0000 & 0.1540 & 0.3915 \\
\hline Ownership of land & -0.0440 & 0.0786 & -0.56 & 0.5760 & -0.1982 & 0.1102 \\
\hline Food decisions & 0.0392 & 0.0593 & 0.66 & 0.5080 & -0.0770 & 0.1554 \\
\hline Paid employment & 0.0706 & 0.0450 & 1.57 & 0.1170 & -0.0176 & 0.1587 \\
\hline
\end{tabular}




\begin{tabular}{|l|c|c|c|c|c|c|}
\hline Household wealth score & $0.0001 * *$ & 0.0000 & 14.97 & 0.0000 & 0.0000 & 0.0000 \\
\hline Partner's education & $0.1059^{*}$ & 0.0533 & 1.99 & 0.0470 & 0.0013 & 0.2104 \\
\hline Age of household head & 0.0029 & 0.0020 & 1.41 & 0.1600 & -0.0011 & 0.0069 \\
\hline Size of household & 0.0166 & 0.0207 & 0.81 & 0.4200 & -0.0238 & 0.0572 \\
\hline Residence & $0.1502 * *$ & 0.0539 & 2.83 & 0.0050 & 0.0460 & 0.2545 \\
\hline Coverage by insurance & $0.3478^{* *}$ & 0.0835 & 4.16 & 0.0000 & 0.1837 & 0.5110 \\
\hline Adequate ANC attendance & $0.2462^{* *}$ & 0.0434 & 5.67 & 0.0000 & 0.1611 & 0.3314 \\
\hline Place of ANC attendance & $0.9608^{* *}$ & 0.1154 & 8.33 & 0.0000 & 0.7347 & 1.1870 \\
\hline Use of FP & $0.1789 * *$ & 0.0505 & 3.55 & 0.0000 & 0.0780 & 0.2778 \\
\hline Number of previous births & $-0.1179 * *$ & 0.0182 & -6.48 & 0.0000 & -0.1536 & -0.0823 \\
\hline Time of the subsidy & $0.1670^{* *}$ & 0.0435 & 3.84 & 0.0000 & 0.0818 & 0.2523 \\
\hline Residuals & -0.0832 & 0.0491 & -1.7 & 0.0900 & -0.1794 & 0.0129 \\
\hline Intercept & $-1.5351^{*}$ & 0.2407 & -6.38 & 0.0000 & -2.0069 & -1.0632 \\
\hline
\end{tabular}

Number of obs.=4751; LR chi² (19) =1150.71; Prob > chi $^{2}<0.0001 ;$ Pseudo $\mathbf{R}^{2}=0.2866$; Log likelihood $=-2310.9642$

$* \mathrm{p}$ values $<0.05 ; * * \mathrm{p}$ values $<0.01$

From the second stage probit model, it emerged that there are positive and negative determinants of choice between an institutional and home delivery during the era of the subsidy. Factors positively associated with choice for an institutional birth included an increase in woman's age, higher education attainment, engaging in some form of paid employment, independence in making food decisions, a higher partner's education attainment and living in households with older heads. Additionally, living in an urban environment, possessing health insurance, a household with a higher wealth index score, access to adequate ANC, attendance to ANC in a health facility, access to family planning and delivery during the time of the subsidy were positively associated with institutional births.

On the other hand, variables such as women from large-sized households, a high number of experienced births, owning land, alone or jointly with spouse, being married, being affiliated to Christian religion and originating from a county with a high poverty headcount rate were negatively associated with choosing an institutional birth. 


\section{Average marginal effects}

Average marginal effects for choice between a health facility and home delivery were estimated using the explanatory variables and are presented on Table 4.

Table 4: Average marginal effect for choice between health facility and home birth $(N=4,772)$

\begin{tabular}{|l|c|c|c|c|c|c|}
\hline Home delivery as the & \multirow{2}{*}{$\mathbf{d y} / \mathbf{d x}$} & $\mathbf{S} . \mathbf{E}$. & \multirow{2}{*}{$\mathbf{z}$} & \multirow{2}{*}{$\mathbf{P}>\mathbf{z}$} & \multicolumn{2}{|c|}{$\mathbf{9 5 \%}$ C.I. } \\
\hline Weference & $0.0052^{* *}$ & 0.0015 & 3.39 & 0.0010 & 0.0022 & 0.0083 \\
\hline Marital status & -0.0283 & 0.0224 & -1.26 & 0.2060 & -0.0721 & 0.0156 \\
\hline Religious affiliation & -0.0144 & 0.0165 & -0.87 & 0.3820 & -0.0467 & 0.0179 \\
\hline Poverty headcount rate & $-0.0024^{* *}$ & 0.0006 & 3.76 & 0.0000 & 0.0011 & 0.0036 \\
\hline Woman's education & $0.0763^{* *}$ & 0.0166 & 4.6 & 0.0000 & 0.0438 & 0.1088 \\
\hline Owning land & -0.0106 & 0.0216 & -0.49 & 0.6240 & -0.0530 & 0.0318 \\
\hline Paid employment & 0.0195 & 0.0124 & 1.58 & 0.1150 & -0.0047 & 0.0438 \\
\hline Food decisions & 0.0109 & 0.0163 & 0.67 & 0.5050 & -0.0211 & 0.0429 \\
\hline Urban residence & $0.0426^{* *}$ & 0.0146 & 2.92 & 0.0030 & 0.0141 & 0.0712 \\
\hline Wealth index factor score & $0.0000^{* *}$ & 0.0000 & 16.43 & 0.0000 & 0.0000 & 0.0000 \\
\hline Partner's education & $0.0293^{*}$ & 0.0147 & 1.99 & 0.0460 & 0.0005 & 0.0581 \\
\hline Age of household head & 0.0007 & 0.0006 & 1.26 & 0.2090 & -0.0004 & 0.0018 \\
\hline Size of household & -0.0031 & 0.0032 & -0.96 & 0.3350 & -0.0095 & 0.0032 \\
\hline Coverage by insurance & $0.0970^{* *}$ & 0.0228 & 4.24 & 0.0000 & 0.0522 & 0.1417 \\
\hline Adequate ANC attendance & $0.0681^{* *}$ & 0.0119 & 5.74 & 0.0000 & 0.0448 & 0.0913 \\
\hline Place of ANC attendance & $0.2639^{* *}$ & 0.0312 & 8.45 & 0.0000 & 0.2027 & 0.3252 \\
\hline Use of FP & $0.0480^{* *}$ & 0.0138 & 3.48 & 0.0010 & 0.0210 & 0.0751 \\
\hline Number of births & $-0.0329 * *$ & 0.0049 & -6.66 & 0.0000 & -0.0426 & -0.0232 \\
\hline Time of the subsidy & $0.0454^{* *}$ & 0.0119 & 3.82 & 0.0000 & 0.0221 & 0.0688 \\
\hline
\end{tabular}

$* \mathrm{p}$ values $<0.05 ; * * \mathrm{p}$ values $<0.01$

\section{Discussion of the findings}

The choice women make about where to deliver is positively or negatively influenced by multiple factors including individual factors, household factors, economic factors and access to reproductive health services including ANC as posited by Gabrysch and Campbell (6) and are discussed as follows. 


\section{Women individual factors}

A significant and increasing probability for women to choose a health facility delivery with an increase in their own age was observed. Studies identify that increasing maternal age increases the risk for adverse maternal outcomes such as stillbirths and peri-natal deaths and the need for interventions including a need for caesarian delivery. This might prompt the women to plan for a health facility delivery (7). It is probable that as the women grow older, they anticipate these risks and as a precautionary measure plan for a health facility delivery. In addition, increasing age grants women autonomy, expanded space to articulate their preferences with confidence, and experience reduced reliance of relatives to make critical decisions. Further, older women are more likely to have been persuaded (through their own experiences) that health institutions are acceptable and safe for delivery.

Education appears to exert a strong positive influence on decision-making for place of birth. Attainment of post-primary education by the women and their partners shows higher probabilities of electing a delivery in a health facility in concurrence with other studies (8). Education's capacity to empower women and their partners to negotiate and make rational decisions has been proven by investigators in similar socio-economic settings $(9,10)$. It is plausible that the ability to process the benefits of a health facility delivery versus the complications, which might occur from a home delivery increase with higher education attainment further driving women and their spouses to make risk averse decisions. These findings validate the value of education as an investment to achieving better health outcomes.

The role of the shared decision-making and influence of the women's social environment including family and household members portrays mixed results. Surprisingly, women who were 
married appeared to be less likely to deliver in a health facility, a concurrence with other studies which suggest the dominance of men and their extended family in negatively influencing decision-making that guarantees safety for pregnant women(9-12). Further, an increase in the household size, a crude measure of domestic burden and dependency, seems to have a negative influence on the choice for a safe place for delivery. Conversely, increasing age of the household head appears to positively impact choice making in favor of facility delivery further affirming evidence about their role in influencing reproductive decisions. An increase in age could mean increased maturity and willingness of household heads to play a supportive role in encouraging safe reproductive choices. Further, older heads especially if they are spouses, are likely to experience reduced influence from relatives and the community and older heads are likely to enjoy some space to make independent decisions. No meaningful associations were established regarding how particular religious beliefs influenced the choice of place of birth.

The proxy determinants of women's autonomy showed mixed results in this study hence concurring with existing literature (13). First, women with paid employment had a higher probability of experiencing a health facility delivery supporting existing literature, which posits that participation in paid labor force is an important determinant of women's ability to make decisions to access reproductive health services. This implies that women have disposable resources within their control to facilitate access to services such as to cater for their transport costs and to meet the direct costs of services. Similar to findings from a study in Ghana(14), decision making on food and ownership of land were weakly associated with the choice women make regarding where the place of delivery would be. The mixed results are not unique. A analysis published in 2019 using recent demographic health survey (DHS) data from 31 countries in sub-Saharan Africa (SSA) found weak associations, and in some countries no 
relationship, between measures of autonomy and access to pregnancy related services (15). It is plausible that factors not included in the survey including cultural beliefs and economic inequalities distributed across the women who participated in the survey might have a greater effect on birthing decisions.

\section{Social environment}

The findings from this analysis identify the household as a critical determinant of the choice of place of birth. Women from poor households were found to have a higher probability of not delivering in a health facility, which validates studies in the SSA region. A population-based study conducted in Tanzania established comparable results(16). Even though delivery services have been subsidized, this does not mean that access to services is absolutely cost free. Similarly, a study conducted in Kenya associated access to delivery services with resource needs to cater for transport, meals, medical items absent at the facilities and opportunity costs related to income loss when relatives accompany the women to the health facility(17). Although these costs might appear miniscule, compared to what is covered by the subsidy, poor households experience disproportionate negative consequences when they incur minimal costs. These findings imply that women from poor households begrudgingly persevere home deliveries even when their lives are at risk.

Similar to our study, a Tanzanian study (16) identified that women from households that possessed health insurance were more likely to delivery in a health facility. These findings are consistent with analysis conducted using data from KDHS 2008-9, which highlighted that $7 \%$ of women who possessed insurance at that time were 23 percentage points more likely to deliver in a health facility(18). Coverage by insurance remains a critical influencer of accessing health services(19). It is commendable that a 5\% increase in insurance coverage was observed between 
the 2008-9 and 2014 demographic surveys. Apart from this, it appears that the higher concentration of health institutions in urban centres in Kenya is favorable for women making choices in favor of health facility deliveries. The distance women would have to cover to reach a health facility determines if they will choose a facility for delivery and as Mwaliko et al (2014) argue, investing in building and equipping comprehensive reproductive facilities is a meaningful approach to entice women to consider seeking professional assistance during birth.

\section{Interaction with the health system}

This study establishes that women who made previous favorable decisions and accessed adequate ANC, attended ANC in a health facility, and used FP methods tended to make consistent decisions when selecting the place of delivery. Women who used FP are likely to have spaced their pregnancies allowing them to have sufficient resources to access ANC, afford a health facility delivery and sustain utilization of beneficial reproductive services. Access to reproductive services provides clinicians with opportunities to offer health education, identify danger signs in pregnancy and recommend specific interventions to the women including facility delivery, thus optimizing future utilization. Furthermore, increased experience with health services assists to dissuade existing cultural and negative beliefs about the usefulness and appeal of health facilities further expanding agency for utilization.

This study has established that with increasing number of births, women shy away from making decisions that favor deliver in a health facility. These findings are comparable to studies, which document that women with three or more children are two times less likely to deliver in a health facility(20). We contend that women who experienced several uncomplicated deliveries possess limited motivation to deliver in a health facility. Further, women are more likely to experience 
easier deliveries with increasing parity, which increases complacency and reduces the initiative to seek assistance during subsequent births. In circumstances where negative experiences during facility delivery are rampant, women with multiple births are likely to lose their patience and avoid health facilities. Multiple successful births translate to increased dependency, higher domestic expenditures, and reduced fiscal space that reduce willingness to incur cost to access services when cheaper alternatives exist.

More women appear to choose health facility deliveries during the time of the subsidy than before. This is very encouraging news for policy makers because the subsidy appears to yield the intended outcomes replicating results observed in other counties. Subsidies in Rwanda, Burkina Faso, Ghana, Nigeria and Ethiopia resulted in impressive outcomes in skilled birth attendance during delivery(21-23). These Kenyan results show good promise given that this study reports data for the first 15 months of the subsidy when structural implementation challenges were reported (4). With additional optimization, this subsidy has potential to attain better results given that these findings were attained during a transition period when the health function was being fully devolved to the counties and the process was faced by a myriad of teething problems(24).

\section{CONCLUSION AND POLICY RECOMMENDATIONS}

This study has elucidated the determinants of choice making for place of birth among women who experienced deliveries during the era of the maternity subsidy in Kenya. The study has identified that during the time of the subsidy, more women were likely to choose to deliver in a health facility, which highlights the impact of the subsidy towards increasing universal access to skilled births and its inherent potential in reducing unwarranted complications to the mother and unborn child during birth. The findings of this study imply that the maternity subsidy has been 
helpful in driving more women to access institutional births. Emphasis needs to be laid on popularizing the subsidy to the potential beneficiaries, addressing the reported challenges related to its implementation and ring-fencing the allocation of resources to sustain the subsidy. Additionally the subsidy can be expanded to cover a package of comprehensive reproductive health services.

The study has documented modifiable factors, which can empower women and strengthen decision-making and increase decision-making agency towards choosing health facility deliveries. The study contends that higher educational attainment for women and their partners, autonomy of women and engaging women in paid work positively influences decision-making. It is crucial that affirmative approaches that retain more women in education beyond primary school, create more women-friendly employment opportunities and policies that recognize and safeguard women's rights to own assets and enable women to control their own lives are enforced. Low poverty incidence and high domestic wealth are facilitative of positive choices. To address the quandary of low skilled attendance at birth, the government should deliberately invest in national poverty eradication schemes, implement measures that enrich households with domestic resources and reduce fertility rates to reduce dependency, which can lower domestic expenditures.

Policies which address prohibitive religious or cultural beliefs, and mitigate early pregnancies and early marriages should be enforced so that women get pregnant and are married when they are not only old enough to have sufficient agency for independent decision-making but also when they can negotiate safe practices including access to the continuum of safe maternal care services. Further, policymakers should explore disruptive and innovative approaches that can 
expand health insurance coverage and widen access to third party payment systems to facilitate access to births in private and public facilities.

\section{REFERENCES}

1. Pyone T, Smith H, van den Broek N. Implementation of the free maternity services policy and its implications for health system governance in Kenya. BMJ Glob Heal [Internet]. 2017 Nov 1;2(4). Available from: http://gh.bmj.com/content/2/4/e000249.abstract

2. Ministry of Health. Status of implementation of Free Maternity Services ( FMS ) program in the devolved health system in Kenya. 2015;61, i-ix.

3. Terza J V, Basu A, Rathouz PJ. Two-stage residual inclusion estimation: addressing endogeneity in health econometric modeling. J Health Econ. 2008;27(3):531-43.

4. Wamalwa EW. Implementation challenges of free maternity services policy in Kenya: the health workers' perspective. Pan Afr Med J. 2015;22(1).

5. Asule BM, Kwena A, Wambui T. Effects of the free maternity care program on utilization of services at a county referral hospital in Kenya. Kenyan J Nurs Midwifery. 2017;1(2).

6. Gabrysch S, Campbell OMR. Still too far to walk: Literature review of the determinants of delivery service use. BMC Pregnancy Childbirth [Internet]. 2009;9(1):34. Available from: https://doi.org/10.1186/1471-2393-9-34

7. Lampinen R, Vehviläinen-Julkunen K, Kankkunen P. A review of pregnancy in women over 35 years of age. Open Nurs J [Internet]. 2009 Aug 6;3:33-8. Available from: https://www.ncbi.nlm.nih.gov/pubmed/19707520

8. Mwaliko E, Downing R, O'Meara W, Chelagat D, Obala A, Downing T, et al. "Not too far to walk": the influence of distance on place of delivery in a western Kenya health demographic surveillance system. BMC Health Serv Res [Internet]. 2014;14(1):212. Available from: https://doi.org/10.1186/1472-6963-14-212

9. Babalola S, Fatusi A. Determinants of use of maternal health services in Nigeria - looking beyond individual and household factors. BMC Pregnancy Childbirth [Internet]. 2009;9(1):43. Available from: https://doi.org/10.1186/1471-2393-9-43

10. Fotso JC, Mukiira C. Perceived quality of and access to care among poor urban women in Kenya and their utilization of delivery care: harnessing the potential of private clinics? Health Policy Plan [Internet]. 2012 Sep 1;27(6):505-15. Available from: http://dx.doi.org/10.1093/heapol/czr074

11. Wilunda C, Scanagatta C, Putoto G, Takahashi R, Montalbetti F, Segafredo G, et al. Barriers to Institutional Childbirth in Rumbek North County, South Sudan: A Qualitative Study. PLoS One [Internet]. 2016 Dec 15;11(12):e0168083. Available from: https://doi.org/10.1371/journal.pone.0168083

12. Mwifadhi M, A. SJ, K. MA, Brigit O, Hassan M, Marcel T, et al. Factors affecting home 
delivery in rural Tanzania. Trop Med Int Heal [Internet]. 2007 Jun 25;12(7):862-72. Available from: https://doi.org/10.1111/j.1365-3156.2007.01855.x

13. Ahmed S, Creanga AA, Gillespie DG, Tsui AO. Economic Status, Education and Empowerment: Implications for Maternal Health Service Utilization in Developing Countries. PLoS One [Internet]. 2010 Jun 23;5(6):e11190. Available from: https://doi.org/10.1371/journal.pone.0011190

14. Speizer IS, Story WT, Singh K. Factors associated with institutional delivery in Ghana: the role of decision-making autonomy and community norms. BMC Pregnancy Childbirth [Internet]. 2014;14(1):398. Available from: https://doi.org/10.1186/s12884-014-0398-7

15. Chol C, Negin J, Agho KE, Cumming RG. Women's autonomy and utilisation of maternal healthcare services in 31 Sub-Saharan African countries: results from the demographic and health surveys, 2010-2016. BMJ Open [Internet]. 2019 Mar 1;9(3):e023128. Available from: http://bmjopen.bmj.com/content/9/3/e023128.abstract

16. Bintabara D, Nakamura K, Seino K. Improving access to healthcare for women in Tanzania by addressing socioeconomic determinants and health insurance: a populationbased cross-sectional survey. BMJ Open [Internet]. 2018 Sep 12;8(9):e023013-e023013. Available from: https://www.ncbi.nlm.nih.gov/pubmed/30209158

17. Mwangome FK, Holding PA, Songola KM, Bomu GK. Barriers to hospital delivery in a rural setting in Coast Province, Kenya: community attitude and behaviours. Rural Remote Heal. 2012;12(2):1852.

18. Were LPO, Were E, Wamai R, Hogan J, Galarraga O. The Association of Health Insurance with institutional delivery and access to skilled birth attendants: evidence from the Kenya Demographic and health survey 2008-09. BMC Health Serv Res [Internet]. 2017;17(1):454. Available from: https://doi.org/10.1186/s12913-017-2397-7

19. Mati K, Adegoke KK, Michael-Asalu A, Salihu HM. Health insurance coverage and access to skilled birth attendance in Togo. Int J Gynecol Obstet [Internet]. 2018 May 1;141(2):181-8. Available from: https://doi.org/10.1002/ijgo.12449

20. Moindi RO, Ngari MM, Nyambati VCS, Mbakaya C. Why mothers still deliver at home: understanding factors associated with home deliveries and cultural practices in rural coastal Kenya, a cross-section study. BMC Public Health [Internet]. 2016 Feb 3;16:114. Available from: https://www.ncbi.nlm.nih.gov/pubmed/26842657

21. Lu C, Chin B, Lewandowski JL, Basinga P, Hirschhorn LR, Hill K, et al. Towards Universal Health Coverage: An Evaluation of Rwanda Mutuelles in Its First Eight Years. PLoS One [Internet]. 2012 Jun 18;7(6):e39282. Available from: https://doi.org/10.1371/journal.pone.0039282

22. De Allegri M, Ridde V, Louis VR, Sarker M, Tiendrebéogo J, Yé M, et al. Determinants of utilisation of maternal care services after the reduction of user fees: A case study from rural Burkina Faso. Health Policy (New York) [Internet]. 2011 Mar 1;99(3):210-8. Available from: http://dx.doi.org/10.1016/j.healthpol.2010.10.010

23. Morgan L, Stanton ME, Higgs ES, Balster RL, Bellows BW, Brandes N, et al. Financial 
Incentives and Maternal Health: Where Do We Go from Here? J Health Popul Nutr [Internet]. 2013 Dec;31(4 Suppl 2):S8-22. Available from:

http://www.ncbi.nlm.nih.gov/pmc/articles/PMC4021697/

24. Tsofa B, Goodman C, Gilson L, Molyneux S. Devolution and its effects on health workforce and commodities management - early implementation experiences in Kilifi County, Kenya. Int J Equity Health [Internet]. 2017 Sep 15;16(1):169. Available from: https://www.ncbi.nlm.nih.gov/pubmed/28911328 


\section{Declarations}

Ethics approval and consent to participate: No consenting procedures were mandated for this study because it employed publicly available data in the DHIS program

Consent for publication: Not applicable

Availability of data and materials: Data applied to generate these findings are publicly available on the DHIS program. The specific elements upon which these findings were generated are available on request from the authors

Competing interests: Authors have no competing interests to declare

Funding: This study was funded by the authors own resources

Acknowledgements: We recognize the support provided by Albert Kimtai Tele during data analysis 